\title{
D-methionine Formulation MRX-1024
}

National Cancer Institute

\section{Source}

National Cancer Institute. D-methionine Formulation MRX-1024. NCI Thesaurus. Code C69140.

A proprietary oral formulation of D-methionine with antioxidant and antimucositis activities. D-methionine formulation MRX-1024 may selectively protect the oral mucosa from the toxic effects of chemotherapy and radiation therapy without compromising antitumor activity. D-methionine may be converted into the L- isomer in vivo, particularly in instances of L-methionine deprivation; both isomers have antioxidant activity which may be due, in part, to their sulfur moieties and chelating properties. L-methionine, an essential amino acid, also may help to maintain the ratio of reduced glutathione to oxidized glutathione in cells undergoing oxidative stress and may provide a source of Lcysteine for glutathione synthesis. 